\title{
KETAHANAN PANGAN
}

\section{Heri Suharyanto*}

\begin{abstract}
Abstrak
Terjadinya kerawanan pangan, disebabkan oleh tidak tercapainya target ketersediaan pangan dan akses terhadap pangan bagi masyarakat. Hal ini menjadi paradox, mengingat Indonesia memiliki lahan yang luas dan subur. Pembangunan ketahanan pangan adalah mencapai ketahanan dalam bidang pangan dalam kondisi terpenuhinya pangan bagi setiap individu/rumah tangga dari produksi pangan nasional, yang tercermin dari tersedianya pangan yang cukup, jumlah dan mutu, aman, merata dan terjangkau di seluruh wilayah Indonesia.
\end{abstract}

Kata kunci: ketahanan pangan, ketersediaan pangan, distribusi pangan.

Definisi dan paradigma ketahanan pangan terus mengalami perkembangan sejak adanya Conference of Food and Agriculture tahum 1943 yang mencanangkan konsep secure, adequate and suitable supply of food for everyone”. Definisi ketahanan pangan sangat bervariasi, namun umumnya mengacu definisi dari Bank Dunia (1986) dan Maxwell dan Frankenberger (1992) yakni "akses semua orang setiap saat pada pangan yang cukup untuk hidup sehat (secure access at all times to sufficient food for a healthy life). Studi pustaka yang dilakukan oleh IFPRI (1999) diperkirakan terdapat 200 definisi dan 450 indikator tentang ketahanan pangan (Weingärtner, 2000). Berikut disajikan beberapa definisi ketahanan yang sering diacu.

Undang-Undang Pangan No.7 Tahun 1996 menyatakan kondisi terpenuhinya kebutuhan pangan bagi rumah tangga yang tercermin dari tersedianya pangan secara cukup, baik dari jumlah maupun mutunya, aman, merata dan terjangkau. Sementara USAID (1992) menyatakan kondisi ketika semua orang pada setiap saat mempunyai akses secara fisik dan ekonomi untuk memperoleh kebutuhan konsumsinya untuk hidup sehat dan produktif. Sedangkan FAO (1997) menyatakan situasi dimana semua rumah tangga mempunyai akses baik fisik maupun ekonomi untuk memperoleh pangan bagi seluruh anggota keluarganya, dimana rumah tangga tidak beresiko mengalami kehilangan kedua akses tersebut.

FIVIMS (2005) menyatakan kondisi ketika semua orang pada segala waktu secara fisik, social dan ekonomi memiliki akses pada pangan yang cukup, aman dan 
bergizi untuk pemenuhan kebutuhan konsumsi dan sesuai dengan seleranya (food preferences) demi kehidupan yang aktif dan sehat. Adapun Mercy Corps (2007) menyatakan keadaan ketika semua orang pada setiap saat mempunyai akses fisik, sosial, dan ekonomi terhadap terhadap kecukupan pangan, aman dan bergizi untuk kebutuhan gizi sesuai dengan seleranya untuk hidup produktif dan sehat.

Berdasarkan definisi tersebut dapat ditarik kesimpulan bahwa ketahanan pangan memiliki lima unsur yang harus dipenuhi: (i) Berorientasi pada rumah tangga dan individu; (ii) Dimensi waktu setiap saat pangan tersedia dan dapat diakses; (iii) Menekankan pada akses pangan rumah tangga dan individu, baik fisik, ekonomi dan sosial; (iv) Berorientasi pada pemenuhan gizi; dan (v) Ditujukan untuk hidup sehat dan produktif (Nuhfil Hanani AR, 2008).

\section{Sistem Ketahanan Pangan}

Sistem ketahanan pangan di Indonesia secara komprehensif meliputi empat sub-sistem, yaitu: (i) ketersediaan pangan dalam jumlah dan jenis yang cukup untuk seluruh penduduk, (ii) distribusi pangan yang lancar dan merata, (iii) konsumsi pangan setiap individu yang memenuhi kecukupan gizi seimbang, yang berdampak pada (iv) status gizi masyarakat. Dengan demikian, sistem ketahanan pangan dan gizi tidak hanya menyangkut soal produksi, distribusi, dan penyediaan pangan ditingkat makro (nasional dan regional), tetapi juga menyangkut aspek mikro, yaitu akses pangan di tingkat rumah tangga dan individu serta status gizi anggota rumah tangga, terutama anak dan ibu hamil dari rumah tangga miskin. Meskipun secara konseptual pengertian ketahanan pangan meliputi aspek mikro, namun dalam pelaksanaan sehari-hari masih sering ditekankan pada aspek makro yaitu ketersediaan pangan. Agar aspek mikro tidak terabaikan, maka dalam dokumen ini digunakan istilah ketahanan pangan dan gizi.

Konsep ketahanan pangan yang sempit meninjau sistem ketahanan pangan dari aspek masukan yaitu produksi dan penyediaan pangan. Seperti banyak diketahui, baik secara nasional maupun global, ketersediaan pangan yang melimpah melebihi kebutuhan pangan penduduk tidak menjamin bahwa seluruh penduduk terbebas dari kelaparan dan gizi kurang. Konsep ketahanan pangan yang luas

\footnotetext{
* Dosen UPM Soshum
} 
bertolak pada tujuan akhir dari ketahanan pangan yaitu tingkat kesejahteraan manusia. Oleh karena itu, sasaran pertama Millenium Development Goals (MGDs) bukanlah tercapainya produksi atau penyediaan pangan, tetapi menurunkan kemiskinan dan kelaparan sebagai indikator kesejahteraan masyarakat. MDGs menggunakan pendekatan dampak bukan masukan.

\section{Swasembada Pangan versus Ketahanan Pangan}

Pada level nasional pengertian ketahanan pangan telah menjadi perdebatan selama tahun 1970 sampai tahun 1980an. Ketahanan pangan nasional tidak mensyaratkan untuk melakukan swasembada produksi pangan karena tergantung pada sumberdaya yang dimiliki. Suatu negara bisa menghasilkan dan mengekspor komoditas pertanian yang bernilai ekonomi tinggi dan barang-barang industri, kemudian membeli komoditas pangan di pasar internasional. Sebaliknya, negara yang melakukan swasembada produksi pangan pada level nasional, namun dijumpai masyarakatnya yang rawan pangan karena ada hambatan akses dan distribusi pangan Stevens et al (2000).

Lassa (2006) dengan mengadopsi Stevens et al (2000), telah memberikan ilustrasi yang sangat baik mengenai negara-negara yang melakukan swasembada pangan dengan kondisi ketahanan pangannya (Tabel 1). Negara-negara kategori A (USA, Canada, Australia, Brunei) memiliki kapasitas pangan yang paling kuat karena memiliki kondisi pangan ideal di mana mereka mampu berswasembada pangan tetapi sekaligus juga memiliki ketahanan pangan yang kuat. Sedangkan Negara C seperti Singapura, Norwegia dan Jepang, mereka sama sekali tidak swasembada pangan tetapi memiliki fondasi ketahanan pangan yang jauh lebih kuat dari Negara-negara kategori B seperti Indonesia, Filipina dan Myanmar.

Tabel 1. Swasembada Pangan dengan Ketidak tahanan Pangan

\begin{tabular}{|l|l|l|}
\hline & \multicolumn{1}{|c|}{ Tahan pangan } & \multicolumn{1}{c|}{ Tidak tahan pangan } \\
\hline \multirow{2}{*}{$\begin{array}{l}\text { Swasembada } \\
\text { Pangan }\end{array}$} & \multicolumn{1}{|c|}{ A } & \multicolumn{1}{c|}{ B } \\
\cline { 2 - 3 } $\begin{array}{l}\text { Tidak Swasembada } \\
\text { Pangan }\end{array}$ & $\begin{array}{l}\text { Contoh: USA, Kanada, Australia, } \\
\text { Brunei, etc. }\end{array}$ & $\begin{array}{l}\text { Contoh: Myanmar, } \\
\text { Indonesia, Filipina }\end{array}$ \\
\cline { 2 - 3 } & $\begin{array}{l}\text { Contoh: Norwegia, Jepang, } \\
\text { Singapura, etc. }\end{array}$ & $\begin{array}{l}\text { Contoh: Malawi, Eritrea, } \\
\text { Kenya, Kongo, East Timor. }\end{array}$ \\
\hline
\end{tabular}

Sumber : Lassa (2006) 
Keterbatasan konsep swasembada pangan ini terjadi di Afrika pada pertengahan tahun 1980 dimana fokus peningkatan produksi untuk mencapai swasembada justru menimbulkan adanya krisis pangan pada masyarakat. Sehingga jelas bahwa ketersediaan pangan pada level nasional tidak secara otomatis menjamin ketahanan pangan pada level individu dan rumah tangga (Borton and Shoham, 1991).

Stevens et al (2000, dalam Lassa, 2006) memberikan ilustrasi yang membedakan secara tegas antara swasembada pangan dengan ketahanan pangan Bostwana, sebagai misal, sebagai Negara dengan pendapatan perkapita sedang tapi mengalami defisit pangan yang kronis karena minimnya lahan pertanian. Strategi ketahanan pangan nasionalnya adalah swasembada tetapi akhirnya lebih berorientasi pada self-reliance. yang mana secara formal mengesahkan kontribusi yang hakiki dari pangan import terhadap ketahanan pangan nasional. Thompson dan Cowan (2000 dalam Lassa, 2006) mencatat perubahan kebijakan dan pendefinisian formal ketahanan pangan dalam kaitannya dengan globalisasi perdangan yang terjadi di beberapa Negara. Contohnya, Malaysia mendefinisikan ulang ketahahanan pangannya sebagai swasembada $60 \%$ pangan nasional. Sisanya, $40 \%$ didapatkan dari import pangan. Malaysia kini memiliki tingkat ketahanan pangan yang kokoh. Ini memberikan ilustrasi yang jelas bahwa ketahanan pangan dan swasembada adalah dua hal yang berbeda. Amartya Sen berhasil menggugat kesalahan paradigma kaum Maltusian yang kerap berargumentasi bahwa ketidak-ketahanan pangan dan kelaparan adalah soal produksi dan ketersediaan semata. Sedangkan dengan mengangkat berbagai kasus di India dan Afrika, Sen mampu menunjukan bahwa ketidaktahanan pangan dan kelaparan justru kerap terjadi karena ketiadaan akses atas pangan bahkan ketika produksi pangan berlimpah, ibarat "tikus mati di lumbung padi”. Kasus gizi buruk di Nusa Tenggara Barat adalah salah satu bukti (Lassa, 2006).

Berdasarkan kenyataan tersebut peneliti dan akademisi menyadari bahwa kerawanan pangan terjadi dimana situasi pangan tersedia tetapi tidak mampu diakses rumah tangga karena keterbatasan sumberdaya ekonomi yang dimiliki (pendapatan, kesempatan kerja, sumberdaya ekonomi lainnya). Hal ini konsisten dengan pendapat 
Sen (1981) bahwa produksi pangan bukan determinan tunggal ketahanan pangan, melainkan hanyalah salah satu faktor penentu. Perbedaan swasembada pangan dengan ketahanan pangan disajikan dalam berikut.

Tabel 2. Perbedaan Swasembada Pangan dengan Ketahanan Pangan

\begin{tabular}{|l|l|l|}
\hline \multicolumn{1}{|c|}{ Indikator } & \multicolumn{1}{|c|}{ Swasembada Pangan } & \multicolumn{1}{c|}{ Ketahanan Pangan } \\
\hline Lingkup & Nasional & Rumah tangga dan individu \\
\hline Sasaran & Komoditas pangan & Manusia \\
\hline Strategi & Substitusi impor & $\begin{array}{l}\text { Peningkatan ketersediaan } \\
\text { pangan, akses pangan, dan } \\
\text { penyerapan pangan }\end{array}$ \\
\hline Output & $\begin{array}{l}\text { Peningkatan produksi } \\
\text { pangan }\end{array}$ & $\begin{array}{l}\text { Status gizi (penurunan : } \\
\text { kelaparan, gizi kurang dan } \\
\text { gizi buruk) }\end{array}$ \\
\hline Outcome & $\begin{array}{l}\text { Kecukupan pangan oleh } \\
\text { produk domestik }\end{array}$ & $\begin{array}{l}\text { Manusia sehat dan produktif } \\
\text { (angka harapan hidup } \\
\text { tinggi) }\end{array}$ \\
\hline
\end{tabular}

Sumber: Nuhfil Hanani AR, 2008.

Swasembada pangan umumnya merupakan capaian peningkatan ketersediaan pangan dengan wilayah nasional, sedangkan ketahanan pangan lebih mengutamakan akses setiap individu untuk memperoleh pangan yang bergizi untuk sehat dan produktif.

\section{Ketahanan Pangan di Indonesia: sebuah tantangan}

Ketersediaan pangan di sebuah negara amat ditentukan oleh kondisi iklim yang kondusif. Musim kemarau yang berkepanjangan, bahaya banjir dan berbagai bencana alam, kebakaran hutan, khususnya di wilayah-wilayah produksi tanaman pangan, akan berdampak pada ketersediaan pangan.

FAO dalam press releasenya bersama-sama dengan WFP pada bulan September 2010, mengemukakan bahwa jumlah penduduk dunia yang menderita kelaparan pada tahun 2010, mencapai 925 juta orang. Situasi ini diperparah dengan semakin berkurangnya investasi di sektor pertanian yang sudah berlangsung selama 20 tahun terakhir, sementara sektor pertanian menyumbang 70\% dari lapangan kerja baik secara langsung maupun tidak langsung. Kekhawatiran akan makin menurunnya kualitas hidup masyarakat, bahaya kelaparan, kekurangan gizi dan akibat-akibat negatif lain dari permasalahan tersebut secara keseluruhan akan 
menghambat pencapaian goal pertama dari Millenium Developmenr Goal (MDGs) yakni eradication of poverty and extreme hunger (Kemenlu RI, 2011).

Persoalan ketahanan pangan menjadi isu yang sangat krusial. Ketahanan pangan dewasa ini, sejak krisis ekonomi hingga sekarang, kemampuan Indonesia untuk memenuhi kebutuhan sendiri kebutuhan pangan bagi penduduk terus menurun, Kenyataan yang ada menunjukkan, bahwa untuk memenuhi kebutuhan pangan bagi lebih dari 20 juta jiwa, dalam periode 1997-2003, Indonesia harus mengimpor bahan pangan diantaranya beras rata-rata 2 juta ton, kedelai 900 ribu ton, gula pasir 1,6 juta ton, jagung 1 juta ton, akhir-akhir ini garam sebesar1,2 juta ton dan menghabiskan devisa negara 900 juta dolar AS pada tahun 2003 (BPS, 2003; Lemlit UGM, 2009).

Pada tahun 2008 dan 2010 telah terjadi krisis pangan di Indonesia. Hal ini disebabkan, adalah sebagai konsekuensi pilihan bangsa Indonesia sendiri yang terlalu menggantungkan penyediaan pangannya dari impor. Ini terbukti dari angka impor pangan Indonesia yang terus meningkat dari tahun ke tahun. Tahun 2007, pemerintah memutuskan mengimpor komoditi pangan, meliputi 1,5 ton besar dan 1,5 juta ton kedelai. Untuk beras, angka tersebut naik sekitar 78,5\% dari tahun 2006 yang hanya sebesar 840 ribu ton. Sedangkan untuk kedelai, angka tersebut naik 25 persen dari tahun 2006 yang berjumlah 1,2 juta ton (berdasarkan catatan tahun 2007 Serikat Petani Indonesia). Hal ini tentu sangat berbahaya bagi kemandirian dan ketahanan pangan Indonesia, karena ketahanan pangan yang kuat dicirikan oleh kemandirian yang kuat (Christin Sinaga, 2011).

Salah satu upaya kemandirian yang kuat adalah melalui revitalisasi pertanian. Revitalisasi pertanian, perikanan dan kehutanan (RPPK) yang telah dicanangkan Presiden RI tanggal 11 Juni 2005 di Jatiluhur, Jawa Barat, mengamanatkan memfokuskan pada peningkatan kapasitas produksi nasional untuk komoditas pangan strategis yaitu padi, jagung, kedelai, tebu dan daging sapi. Sebagai gambaran umum, pada tahun 2004, untuk komoditas padi, kita mampu melepaskan diri dari impor, malah berdasarkan perkiraan kita sudah surplus dua juta ton berupa stok di masyarakat (rumah tangga dan pedagang) dan pemerintah (BULOG); sedangkan untuk empat komoditas lainnya masih tergantung dari impor. 
Secara kuantitas, impor jagung, kedelai, gula dan daging sapi, masing-masing sebesar 11,23\%; 64,86\%; 37,48\%; dan 29,09\% dari kebutuhan (BPPP Dep. Tan 2011).

\section{Persoalan Rawan Pangan}

Pada tahun 2005, harian Kompas memberitakan, banyak anak menderita gizi buruk atau bahkan busung lapar di beberapa wilayah. Misalnya, 66.685 anak di Nusa Tenggara Timur (Kompas, 7/6/2005), sekitar 49.000 anak di Nusa Tenggara Barat (Kompas, 4/4/2005), 425 anak di Boyolali (Kompas, 7/6/2005), 11.368 anak di Sumba Barat (Kompas, 16/6/2005), dan masih banyak lagi, menderita gizi buruk yang sangat memprihatinkan, dan sebagian dari mereka meninggal dunia karena orang tuanya tidak bisa memenuhi gizi anaknya (Asqolani, 2011).

Peristiwa gizi buruk di awal tahun 2005 yang melanda NTB, NTT, Sumba, dan lain-lain itu yang menjadi korban rawan pangan justru adalah para petani miskin yang tinggal di pedesaan. Itu yang sempat diekspose di media, belum terhitung yang lolos dari pengamatan media. Persoalan yang dihadapi pemerintah dalam mengatasi kerawanan pangan menyangkut lima aspek (Deptan, 2009): 1) Ketersediaan pangan, 2) Distribusi pangan, 3) Konsumsi pangan, 4) Pemberdayaan masyarakat, dan 5) Manajemen.

Dari lima aspek di atas, menarik untuk dibahas perihal distribusi pangan. Pada aspek ini permasalahan yang muncul secara teknis meliputi 4 (empat) hal (Deptan, 2009) ialah: (1) Belum memadainya infrastruktur, prasarana distribusi darat dan antar pulau yang dapat menjangkau seluruh wilayah konsumen, (2) belum merata dan memadainya infrastruktur pengumpulan, penyimpanan dan distribusi pangan, kecuali beras, (3) sstem distribusi pangan yang belum efisien, dan (4) bervariasinya kemampuan produksi pangan antar wilayah dan antar musim menuntut kecermatan dalam mengelola sistim distribusi pangan agar pangan tersedia sepanjang waktu di seluruh wilayah konsumen. Sementara yang berkaitan dengan aspek sosial ekonomi adalah: (1) belum berperannya kelembagaan pemasaran hasil pangan secara baik dalam menyangga kestabilan distribusi dan harga pangan, (2) masalah keamanan jalur distribusi dan pungutan resmi pemerintah pusat dan daerah serta berbagai pungutan lainnya, sepanjang jalur distribusi dan pemasaran telah menghasilkan biaya distribusi yang mahal dan akibatnya meningkatkan harga produk pangan. 
Sementara itu Galih Nugraha (2009), menjelaskan ada empat akar permasalahan pada distribusi pangan yang dihadapi: (1) dukungan infrastruktur, yaitu kurangnya dukungan akses terhadap pembangunan sarana jalan, jembatan dan lainnya, (2) sarana transportasi, yakni kurangnya perhatian pemerintah dan masyarakat didalam pemeliharaan sarana transportasi kita, (3) sistem transportasi, yang dianggap masih kurang efektif dan efisien. Selain itu juga kurangnya koordinasi antara setiap moda transportasi mengakibatkan bahan pangan yang diangkut sering terlambat sampai ke tujuan, (4) masalah keamanan dan pungutan liar, yakni pungutan liar yang dilakukan oleh preman sepanjang jalur transportasi di Indonesia masih sering terjadi.

Untuk itulah masalah rawan pangan segera dicarikan solusinya, agar ketersediaan pangan dapat diwujudkan di seluruh wilayah tanah air. Misalnya, implementasi UU Pokok Agraria no. 5 th. 1960, agar para petani memiliki cukup lahan pertanian untuk keperluan produksi pangan. Perlu adanya perubahan mind set masyarakay, agar yang namanya pangan itu tidak hanya sekedar beras, jagung, tapi ubi-ubian, sagu, dan lain-lain, perlu juga dibudidayakan untuk memenuhi kebutuhan pangan kita. Keanekaragaman pangan inilah yang mungkin bisa menjadi makanan alternatif untuk terbebas dari ancaman kelaparan.

\section{Kesimpulan}

Swasembada pangan masih belum relevan dalam upaya mewujudkan ketersediaan pangan baik nasional maupun internasional khususnya bagi petani. Untuk itu implementasi UU Pokok Agraria no. 5 tahun 1960 tentang land reform segera diimplementasikan, agar para petani memiliki lahan yang cukup untuk produksi pangan. Permasalahan yang dihadapi bangsa Indonesia yang bersangkut degan ketahanan pangan seperti ditulis di depan, layak segera diatasi secara keseluruhan. Persoalan distribusi pangan, harus mendapatkan prioritas, karena bersangkut dengan dampak pada aspek sosial ekonomi, khususnya keamanan dan pungutan liar, sepanjang jalur transportasi di Indonesia, tetap masih marak. Jangan sampai mengirim barang dari pulau Jawa ke Medan misalnya, ongkosnya lebih mahal dibandingkan mengirim barang dari pulau Jawa ke Thailand. 


\section{Daftar Pustaka}

Anonim. Ketersediaan Pangan http://www.deptan.go.id/pesantren/bkp/PSP/ index.htm

Anonim. Solusi dari Rawan Pangan. http://www.poultryindonesia.com/modules.php? name $=$ News \& file $=$ article $\&$ sid $=1520$

Asqolani, Hasan. 2011. Problem Ketahanan dan Nasib Petani, http://sugiarto agribisnis.wordpress.com/2011/04/24/problem-ketahanan-pangan-dannasib-petanil

Anonim, 1996. Undang-Undang Negara Republik Indonesia Nomor 7 Tahun 1996 tentang Pangan. Kantor Menteri Negara Pangan RI.

Anonim, 2000. Undang-Undang Negara Republik Indonesia Nomor 25 Tahun 2000 tentang Program Pembangunan Nasional.

BPPP (Badan Penelitian dan Pengembangan Pertanian) Departemen Pertanian. Kondisi Ketahanan Pangan di Indonesia. Sumber: http://www.pustaka. litbang.deptan.go.id/bppi/lengkap/bpp050004.pdf

Hanani AR, Nuhfil, 2008. Ketahanan Pangan, Sumber: http://ajangberkarya. wordpress.com/2008/05/20/pengertian-ketahanan-pangan/

Husodo, Siswono Yudo, 2001. Kemandirian di Bidang Pangan, Kebutuhan Negara Kita. Makalah Kunci pada Seminar Nasional Teknologi Pangan, Semarang, 9-10 Oktober 2001.

Jonatan, Lassa. Politik Ketahanan Pangan Indonesia 1952-2005. Sumber: http://www.zef.demoduleregistermedia3ddf_Politik\%20Ketahanan\%20 Pangan\%20Indonesia\%201950-2005.pdf

Lemlit UGM. 2009. Ketahanan Pangan. Sumber: lemlit.ugm.ac.id/Agro/ download/ white_paper.doc

Nugraha, Galih. 2009. Meningkatkan Ketahanan Pangan Indonesia berbasis Sumber Daya Lokal. Sumber: http://www.nugrohogalih.wordpress.com/ 2009/02/06/meningkatkan-ketahanan-pangan-indonesia-berbasis-sumberdaya-lokal.htm

Sinaga, Lidya Christin. Mempertanyakan Kembali Ketahanan Pangan Indonesia. Sumber: $\quad$ http://www.politik.lipi.go.idindex.php/inkolompolitik_nasional374 mempertanyakan kembali-ketahanan-pangan-Indonesia.htm

Suryana, Achmad, 2001. Kebijakan Nasional Pemantapan Ketahanan Pangan. Makalah pada Seminar Nasional Teknologi Pangan, Semarang, 9-10 Oktober 2001. 